\title{
Percepções de alunos de LE sobre tarefas de enfoque gramatical realizadas on-line
}

Roberval Araujo de Oliveira

Unileste MG

\begin{abstract}
A Comunicação Mediada por Computador (CMC) tem trazido diversos benefícios para o processo de ensino/aprendizagem de línguas. A literatura que versa sobre o tema, no entanto, pouco tem dado atenção às reações e percepção dos aprendizes sobre a introdução da CMC à sala de aula de línguas. Nosso estudo busca investigar como um grupo de alunos de um curso semipresencial de ILE perceberam e reagiram a uma atividade de enfoque gramatical baseado na WWW.
\end{abstract}

CMC has promoted numerous benefits to the language learning process. The literature on this theme, how ever, has paid little attention to what students have to say about their own reactions to the introduction of CMC to the FL classroom. O ur study attempts to investigate how a group of students in an online writing course perceived and reacted to a web-based grammar activity.

\section{Introdução}

Com as rápidas mudanças tecnológicas que as salas de aula de língua estrangeira (LE) têm testemunhado desde a última década, novas ferramentas têm-se somado às anteriormente existentes, dentre elas destacando-se o computador e a internet, componentes da chamada Comunicação Mediada por Computador (CMC). Na sala de aula, a aliança da necessidade de instrução formal a esses novos meios tem algo de inusitado: a facilidade de acesso a fontes de informação e a facilitação da realização de tarefas, ambas tidas como peculiares ao meio eletrônico, têm sido apregoadas como promotoras de um processo de aprendizagem mais eficaz, participativo e igualitário em um grau nunca antes experimentado na história do ensino de LE.

Todavia, essa impressão do efeito positivo do meio eletrônico na aprendizagem fundamenta-se, sobretudo, em dados externos ao ap rendiz, tais como os resultados quantitativos de um curso ou tarefas via computador, índices de progresso e rendimento dos alunos, e sua 
freqüência de participação. Essa área ainda é carente de investigações sobre como o aprendiz percebe e reage ao uso desses meios no processo de ensino/aprendizagem. Assim, o estudo relatado neste artigo buscou investigar quais são as percepções dos alunos de um curso de produção escrita em inglês sobre tarefas de enfoque gramatical realizadas com o auxílio do computador. Além disso, esse ensaio tenta traçar relações entre as percepções reveladas pelos mesmos alunos e os elementos de sua história de ap rendizes e, por vezes, sua experiência como professores de língua.

\section{0 ensino/aprendizagem de gramática e a instrução em LE via meio eletrônico}

\subsection{Estudos sobre o papel do meio eletrônico no ensino/ aprendizagem de línguas}

Há uma vasta literatura sobre o papel dos meios eletrônicos na sala de aula de LE, grande parte da qual disponibilizada na própria internet. Dentre esses incontáveis trabalhos, destaca-se o de Graus (1999), dissertação de mestrado que faz um apanhado e uma avaliação das possibilidades pedagógicas da internet na sala de aula. Em termos gerais, a dissertação de Graus compartilha das impressões otimistas sobre o papel educacional da internet expressa pelos autores que ele revisa (VAN ASSCHE, 1998; CORBETT, 1998; BELISLE, 1996 e LeLOUP \& PONTERIO, 1996, por exemplo) mas também por muitos outros não incluídos em seu trabalho. Tal visão apóia-se parte em resultados de pesquisas sobre os efeitos das tecnologias da CMC no ensino de línguas, e parte nas teorias educacionais e, mais estritamente, sobre a aprendizagem de línguas, para concluir que, grosso modo, o papel dos meios eletrônicos na sala de aula de LE é positivo. Dentre os benefícios citados por Graus e outros autores destacam-se: 1) formação de sujeitos letrados na Tecnologia da Informação e Comunicação, supostamente um pré-requisito para um indivíduo ser bem-sucedido conquanto profissional e cidadão do século 21 (VAN ASSCHE, 1998; BELISLE, 1996); 2) promoção de um processo educacional fundado na tolerância e respeito à multiplicidade cultural, dado que a internet possibilita o contato entre pessoas situadas nos mais diversos cantos do planeta (VAN ASSCHE, 1998); 3) acesso a fontes autênticas de informação (ROGER, 1998; LeLOUP \& 
PONTERIO, 1996), não obstante a qualidade questionável de muito do que está disposto na WWW (CORBETT, 1998); 4) criação de oportunidades reais de comunicação, por meio de ferramentas como o e-mail, que promovam a troca de idéias e opiniões e propiciem uma abordagem de ensino nos parâmetros comunicativos (VAN ASSCHE, 1998); 5) compatibilização das técnicas de ensino à predominância de um estilo de aprendizagem táctil-visual na população estudantil de hoje (GRAUS, 1999; LeLO UP \& PONTERIO, 1996); 6) re-configuração dos padrões de interação em "sala de aula", o que torna a participação dos sujeitos envolvidos no processo de aprendizagem mais igualitária e 0 aprendiz mais autônomo (PARREIRAS, 2000; PAIVA, 1999; WARSCHAUER, 1998); 7) exposição a novos tipos de input, tanto em termos quantitativos quanto qualitativos (PENNINGTON, 1996); 8) acesso a fontes autênticas da língua-alvo, traço de grande relevância teórica e pedagógica nas abordagens mais contemporâneas de ensino/aprendizagem de línguas que, de certa forma, relativiza a restrição apontada na alínea 3, concernente à qualidade do material que a internet disponibiliza.

A literatura que trata dos usos das novas tecnologias no ensino/ aprendizagem de LE enfoca ainda questões de caráter político, social e discursivo inerentes à aprendizagem via meio eletrônico. Warschauer e Lepeintre (1997), por exemplo, promovem uma discussão sobre os parâmetros relacionais típicos da rede mundial de computadores. Os autores contrastam dois efeitos potenciais da CMC sobre as estruturas de poder da sala de aula: a geração de igualitarismo e a intensificação do controle exercido via Tecnologias de Informação e Computador (TIC). 0 primeiro efeito é descrito nos termos da pedagogia do oprimido de Paulo Freire; o segundo, nos termos do conceito de 'panopticon' foucaultiano. Outros estudos também abordam questões de quilate semelhante. Pennington (1996), por exemplo, trata desses tópicos da Aprendizagem de Línguas Assistida por Computador (ALAC) em termos da noção de empowerment, concessão de uma forma de poder ao usuário/ aprendiz pelos meios da CMC. Warschauer (1998) também dá ao assunto uma perspectiva em parte sociocultural, a respeito da qual conclui, após sintetizar dados da literatura relevante, que, tanto no plano da interação como socialização quanto como atividade de fala e como aprendizagem (apprenticeship), os benefícios são claros: os sujeitos envolvidos nesse tipo de discurso ganham em habilidades sociais, controle da própria expressão na língua e também em aprendizado. 


\subsection{As percepções dos aprendizes sobre interação e instrução gramatical via meio eletrônico}

0 termo "percepções dos ap rendizes" tem sido usado de maneira não sistemática e esparsa para referir-se a como o aluno nota, processa e responde a aspectos e componentes do processo de aprendizagem. Trata-se de um conceito já legitimado pela comunidade e prática lingüísticas. Ele pode ser usado de modo a abranger os termos "crença" (CARVALHO, 2000; GALIZZI, 2000; BARCELOS, 1995; HORWITZ, 1987) e "atitude" (GRAUS, 1999; WARSCH AUER, 1996). O que esses diversos termos têm em comum é o intuito de denominar um sistema de variáveis ligadas à subjetividade do aprendiz: o que ele percebe, pensa e faz do processo de aprendizagem em toda a sua complexidade.

Putnam (2000) e Parreiras (2000) utilizam-se da denominação 'percepções do estudante' e Isbell \& Reinhardt (1999) falam alternadamente em percep ção, atitude e resposta. Esses quatro autores aplicam o termo percep ção como definido acima para estudantes de língua em contexto de interação eletrônica. Em essência, to dos esses termos são voltados para o aprendiz, no sentido de que eles almejam uma perspectiva do aluno no processo de aquisição da língua. Independentemente de qual palavra é ado tada para denominar esse sistema, as pesquisas já realizadas sobre o tema revelaram invariavelmente uma relação entre as percepções sobre o meio eletrônico e a auto-avaliação dos aprendizes sobre seu rendimento no curso (CARVALHO, 2000; HORWITZ, 1987).

No restante deste trabalho, descrevemos os procedimentos e relatamos os resultados da pesquisa que realizamos sobre as percepções de um grupo de alunos de um curso de produção escrita em inglês língua estrangeira sobre o uso, benefícios, vantagens e desvantagens da CMC numa tarefa de enfoque gramatical realizada online. Na seção que se segue 3 - Procedimentos, descrevemos os componentes e os participantes do nosso estudo, assim como as perguntas que o orientaram. Na seção 4 - Resultados - abordamos as percepções dos participantes e suas relações com as suas experiências prévias de aprendizes e, por vezes, de professores de língua e também com os seus perfis de aprendiz. 


\section{Procedimentos}

0 estudo aqui relatado foi realizado em uma turma de produção de textos em inglês língua estrangeira do programa de graduação da Faculdade de Letras da UFMG. 0 curso foi ministrado por um professor e por seu estagiário de mestrado e também autor do presente texto. Utilizou-se um dos laboratórios de informática da referida faculdade para os encontros presenciais. Tratava-se de um curso semipresencial, no qual os alunos tinham um encontro presencial semanal para orientações pelos professores, execução de tarefas on-line, entrega de tarefas, etc. Parte das atividades dos alunos devia necessariamente ser realizada via internet entre os encontros semanais. Contudo, muitos dos alunos não tinham acesso à WWW em casa e, por isso, realizavam as atividades do curso quase que integralmente no laboratório. A atividade descrita neste texto foi uma de duas tarefas de enfoque gramatical realizadas no curso (a outra foi sobre o uso de pronomes relativos). Todas as demais tarefas envolviam produção, edição e reescrita de textos.

\subsection{Etapas da pesquisa}

Identificamos uma dificuldade recorrente da parte dos alunos com o uso do artigo definido em sua produção escrita, razão pela qual optamos pela inclusão de exercícios da WWW, enfocando o sistema de artigos do inglês no conteúdo do curso; decidimos investigar os resultados com os aprendizes, e, sobretudo, as suas percepções sobre a tarefa proposta. 0 procedimento adotado em nosso estudo consistiu em três passos. 0 primeiro, a realização de uma tarefa criada por John Kohl e disponibilizada na internet (http://www.rpi.edu/web/ writingcenter/esl.html). 0 material continha uma descrição de critérios para o uso dos artigos, que era seguida de exercícios com respostas explicativas que remetiam àqueles mesmos critérios. Trata-se de um material de enfoque na forma que, à parte as características exclusivas do hipertexto, muito se assemelhava a uma gramática impressa. Como parte da tarefa, os alunos deveriam entregar comentários sobre suas impressões sobre tal tarefa. Os comentários foram direcionados a duas perguntas previamente fornecidas pelos pesquisadores/professores: 1) Todas as quatro "Dicas de Aprendizagem" Ihe trouxeram algo de novo? quê? 2) Qual é a sua opinião sobre cada uma das três tabelas? 
Elas são claras ou confusas? Por quê? As respostas elaboradas pelos alunos foram entregues tanto via e-mail como por meio impresso. Tais comentários não serviram de fonte de dados para a pesquisa, mas sim de suporte inicial para a formulação dos roteiros das entrevistas (Passo 3).

O segundo passo consistiu na avaliação do uso do artigo pelos alunos, baseada em textos produzidos após uma e 10-12 semanas do início da realização da atividade. Não se trata de uma análise quantitativa que almeja a verificação da eficácia da atividade para a aprendizagem do uso dos artigos. Antes, buscamos nesses dados elementos que pudessem estar relacionados com as impressões reveladas pelos participantes no passo seguinte. Neste último, os informantes foram entrevistados sobre suas percepções da tarefa realizada e do uso da CMC nessa atividade e no curso como um to do. Essas entrevistas foram gravadas em áudio, transcritas e analisadas, e constituem, desse modo, o cerne deste trabalho.

\subsection{Perguntas}

$\mathrm{Na}$ tentativa de uma investigação voltada para a relação entre os dois fatores - uso do meio eletrônico na instrução formal em gramática e percepções dos aprendizes sobre esse uso -, nosso estudo oriento use nas seguintes questões: 1) quais são as percep ções dos alunos sobre a realização, por meio de um meio eletrônico, das tarefas prescritas? 2) uma abordagem que demanda maior autonomia do aluno funciona igualmente para todos os aprendizes? 3) o que as percepções dos alunos a respeito do procedimento de ensino/aprendizagem adotado podem revelar sobre as causas de seus resultados, sejam eles positivos, sejam eles negativos? Naturalmente, essas perguntas serviram de norteadoras na elaboração dos roteiros das entrevistas, juntamente com os comentários escritos dos alunos a respeito da referida tarefa.

\subsection{Participantes}

Os participantes da pesquisa foram alunos de graduação da Faculdade de Letras da UFMG, matriculados em um curso de produção escrita em língua inglesa, do qual o computador era a principal ferramenta. A experiência prévia dos alunos com o computador era bastante variada: alguns já participando de cursos de informática em seus 
estudos e outros tendo, naquele momento, seu primeiro contato com a máquina na sala de aula. Também em termos de experiência profissional, os participantes formavam um grupo heterogêneo: uma possuía certa experiência de ensino para crianças e outra ensinava inglês para adolescentes havia algum tempo. Já uma terceira participante possuía vivência de sala de aula não apenas significativa mas também variada; os demais participantes não haviam tido qualquer experiência prévia como professores da língua. Dos 33 alunos que freqüentaram o curso inicialmente, seis dos mais assíduos constituíram o grupo que embasou nosso estudo. Esse grupo formou-se após a realização da tarefa, quando seus integrantes, ao tecerem comentários escritos sobre essa tarefa, foram solicitados a conceder entrevistas, cujos roteiros foram baseados nesses comentários. Uma vez que não havia o intuito de comprovar a superio ridade do procedimento que adotamos em relação a outros existentes, não houve grupo de controle nem de tratamento. 0 enfoque central do nosso estudo foi, portanto, nas percepções dos alunos.

\section{Resultados}

As entrevistas geraram informação relativa a três tipos de percepção: 1) a utilidade potencial da tarefa para a promoção da aquisição/ aprendizagem dos artigos; 2) a preferência dos aprendizes por um meio tradicional ou por um meio eletrônico de instrução; e 3) as possíveis vantagens de utilizar um material da internet. As duas últimas categorias podem parecer a princípio indistintas. Contudo, quando perguntamos aos informantes sobre quais vantagens eles viam no uso da internet para o estudo do artigo definido, o que tínhamos em mente eram suas percepções sobre os benefícios potenciais que o material e o meio poderiam oferecer a qualquer aprendiz, enquanto que a outra questão enfoca suas preferências pessoais.

\subsection{Sobre a utilidade da tarefa e o material utilizados}

No geral, as declarações dos alunos são visivelmente antitéticas, mas não de uma forma incongruente. Se tomarmos a opinião deles sobre a tarefa e o material como recurso para a sua própria aprendizagem 
separadamente de sua avaliação dos mesmos recursos para outros aprendizes/professores, então as suas percepções parecem de fato contraditórias. Contudo, o texto completo das entrevistas e nossa apreciação final do desempenho dos entrevistados confirmam que os informantes Andréa, Craig, Helen e Rita ${ }^{1}$ discerniam entre um valor pessoal do material utilizado e um valor que ele potencialmente teria para outros aprendizes.

\section{QUADRO 1}

Utilidade da tarefa para o desenvolvimento pessoal do uso do artigo

\begin{tabular}{|c|c|}
\hline Participante & Resumo \\
\hline 1. Andréa & $\begin{array}{l}\text { Acha o exercício bom como uma revisão do assunto, mas } \\
\text { considera a explicação confusa para iniciantes, pois contém } \\
\text { informação em excesso e o formato do texto não é atraente, o } \\
\text { que torna a leitura enfadonha e os exemplos difíceis de distinguir. } \\
\text { Diz que o conteúdo era na sua maioria conhecido e que ela não } \\
\text { conseguiu reter nenhuma informação nova. }\end{array}$ \\
\hline 2. Craig & $\begin{array}{l}\text { Diz que pouquíssima coisa no material era novidade para ele. Ainda } \\
\text { assim, considera o material bom para iniciantes, não complicado } \\
\text { e os exercícios bem elaborados. Considera o design da página bom. }\end{array}$ \\
\hline 3. Frances & $\begin{array}{l}\text { Considera o material um "teste traiçoeiro", embora afirme que as } \\
\text { definições eram em sua maio ria claras, e as respostas com } \\
\text { explicação dos exercícios "muito interessantes". Acha que houve } \\
\text { informação em excesso, mas aprova sua disposição visual. } \\
\text { Considera o material uma boa fonte de informação, embora não } \\
\text { para o seu caso em particular. }\end{array}$ \\
\hline 4. Margarida & $\begin{array}{l}\text { Acha o design da página interessante, organizado e atraente e a } \\
\text { quantidade de informação suficiente. Considera o conteúdo novo } \\
\text { eútil para ela e destaca a qualidade da explicação dada no material. }\end{array}$ \\
\hline 5. Helen & $\begin{array}{l}\text { Considera as dicas da página 'pertinentes' e 'práticas'. Diz que a } \\
\text { informação não foi excessiva. Declara que a tarefa tornou-a mais } \\
\text { atenta ao seu próprio uso dos artigos, sobretudo na escrita. }\end{array}$ \\
\hline 6. Rita & $\begin{array}{l}\text { Diz que o material não continha nada que fosse realmente novo } \\
\text { para ela, mas que o mo do como é apresentado é "menos } \\
\text { complicado". Considera o design da página bom e diz que não } \\
\text { é muito diferente do de uma gramática impressa. }\end{array}$ \\
\hline
\end{tabular}

${ }^{1}$ O s nomes dos informantes são, na verdade, codnomes. 
A avaliação dos informantes a respeito do material utilizado foi, no geral, positiva. 0 único comentário negativo recorrente referiu-se à quantidade de informação, considerada por alguns deles como excessiva. As opiniões quanto ao uso do material em sala variaram consideravelmente. Andréa sugere que a utilidade do material depende sobremaneira de cada aluno. "Dependendo do aluno pode ser que sirva", diz ela e completa "mas isso é muito pessoal também, né?". Frances diz que só o usaria com aprendizes jovens, porque eles gostam de usar o computador: "Acho que um aluno jovem se sentiria mais atraído porque é no computador". Craig diz que, se o aprendiz estiver determinado a aprender e o seu interesse for em artigos, ou se ele tiver que fazer uma tarefa semelhante à utilizada em nosso estudo, então 0 material em questão seria uma boa opção, que interessaria aos alunos. No mais, Craig ainda afirma que o material interessaria mais se fosse "ainda mais interativo".

\subsection{Preferência por um meio tradicional ou eletrônico de instrução}

As preferências dos informantes por um meio eletrônico ou tradicional de instrução, assim como suas percepções das possíveis vantagens de utilizar recursos da internet revelaram três posicionamentos distintos: nitidamente contra uma abordagem instrucional baseada na CMC (Craig), a favor dela (Margarida, Helen e Rita) e indiferente a ela (Andréa e Frances). As percep ções dos informantes sobre as vantagens do uso de cada meio revelaram-se ainda consistentes com suas preferências por um certo, ou mesmo com a ausência de uma preferência. Às vezes essa consistência parece existir, apesar da relativa inexperiência do aluno com um meio específico. Desse modo, Frances, que declarou ter muito pouca experiência com o uso do computador, considera a tarefa "uma forma diferente de aprender as coisas", e também atribui ao meio eletrônico diversas qualidades como rapidez, facilidade de uso e disponibilização de informação. 
QUADRO 2

Preferências por um meio eletrônico ou tradicional

\begin{tabular}{l|l}
\hline Participante & \multicolumn{1}{c}{ Resumo } \\
\hline 1. Andrea & $\begin{array}{l}\text { Diz que o meio não faz diferença para ela. Enfatiza a qualidade } \\
\text { do material e design da página como determinantes em sua } \\
\text { escolha. }\end{array}$ \\
& $\begin{array}{l}\text { Relata sua própria experiência para sustentar a opinião de que, } \\
\text { embora ele goste muito de usar a internet, ainda não se sente } \\
\text { muito à vontade num contexto ALAC. Diz que as aulas on-line } \\
\text { permanecem vagas e que ele é mais dado a livros e professores } \\
\text { em interação em tempo real com os alunos. }\end{array}$ \\
3. Frances & $\begin{array}{l}\text { Não declara nenhuma preferência por um meio específico, mas } \\
\text { diz preferir ler textos em livros do que na tela do computador. } \\
\text { Diz que fazer a tarefa via internet foi útil para que ela ganhasse } \\
\text { experiência com os programas do computador. } \\
\text { 4. Margarida }\end{array}$ \\
$\begin{array}{l}\text { Pensa que a internet é "a melhor forma" de exercitar o uso dos } \\
\text { artigos e diz que acha mais interessante do que usar material } \\
\text { impresso. }\end{array}$ \\
$\begin{array}{l}\text { Diz que usar a internet é mais fácil, ao que torna o acesso a } \\
\text { diferentes documentos mais dinâmico. Destaca suas próprias } \\
\text { preferências de estilos de aprendizagem ao declarar que pode } \\
\text { visualizar melhor as coisas na tela do computador do que numa } \\
\text { página de livro. } \\
\text { Declara uma preferência entusiasta pelo meio eletrônico. Diz } \\
\text { que, a única razão para ela recorrer a materiais impressos, seria } \\
\text { a não existência de um bom material ou qualquer material na } \\
\text { rede mundial de computadores. }\end{array}$ \\
\hline
\end{tabular}

\subsection{Sobre as possíveis vantagens de utilizar um material da internet}

Todos os alunos mostram ter visões consistentes de utilizar um ou outro meio para a realização da tarefa. Às vezes suas percepções enfocam as vantagens práticas do meio, tais como economia de tempo e disponibilidade (Helen e Rita). Outras vezes ela se volta para aspectos mais afetivos do processo de aprendizagem, como a interação presencial, na qual o contato oral/verbal, visual e/ ou corporal se tornam possíveis. Craig, por exemplo, lamenta ter passado por um curso simultaneamente presencial e via meio eletrônico, no qual a interação 
entre colegas e professor dava-se quando to dos se encontravam em sala de aula. Nas palavras de Craig, isso seria "assim uma idiotice completa". Destacamos aí a evidência de que as percepções sejam um produto da experiência pregressa e perfil de aprendizagem de cada aprendiz, suposição que tentaremos elaborar a seguir.

QUADRO 3

Possíveis vantagens do uso de materiais encontrados na Internet

\begin{tabular}{l|l}
\hline Participante & \multicolumn{1}{c}{ Resumo } \\
\hline 2. Andréa & $\begin{array}{l}\text { Não aponta quaisquer vantagens. } \\
\text { Vê na interação aluno-aluno e professor-aluno em tempo real } \\
\text { uma grande vantagem das salas de aula tradicionais. Aponta } \\
\text { para a necessidade de critérios concretos para que se opte pela } \\
\text { adoção de meios eletrônicos. } \\
\text { Aponta diversas vantagens dos meios eletrônicos: acessibilidade } \\
\text { das informações, tanto nos limites do computador como na rede } \\
\text { mundial, maior velocidade de acesso, maior capacidade de } \\
\text { armazenamento de dados e facilitação de atividades de } \\
\text { aprendizagem. } \\
\text { Destaca a vantagem de poder checar as respostas de dado } \\
\text { 4. Margarida }\end{array}$ \\
$\begin{array}{l}\text { 5. Hercício de uma página da internet, já que se pode mover de } \\
\text { uma página para outra. }\end{array}$ \\
$\begin{array}{l}\text { Fala em velocidade, dinamismo e atração visual como vantagens } \\
\text { dos meios eletrônicos. } \\
\text { Destaca vantagens, tais como acessibilidade e disponibilidade } \\
\text { de informação, ausência de restrições espaciais e temporais e } \\
\text { a possibilidade de salvar materiais úteis em seu disco rígido. }\end{array}$ \\
\hline
\end{tabular}

\subsection{Relações entre experiência prévia, perfil de aprendiz e percepções sobre a ALAC}

Grande parte das informações eliciadas através das entrevistas dános certa compreensão de variáveis do processo de ap rendizagem dos informantes que não suas percepções da tarefa on-line. Esse 'insight', associado a um conhecimento das personalidades e perfis de ap rendizes dos entrevistados (ambas fundamentadas em observações e anotações feitas durante as aulas e nas entrevistas), levou-nos a concluir que as mesmas variáveis têm algum peso sobre como os 
aprendizes percebem, reagem e valorizam o que eles estudam e a maneira como se espera que eles estudem. Assim, sustentamos a hipótese de que os estilos de ap rendizagem predominantes dos alunos, suas estratégias de aprendizagem mais freqüentes, sua experiência acumulada como aprendizes de LE (inclusive uma vivência anterior de tarefas semelhantes ou de elementos dessa tarefa), assim como seu background educacional global, podem explicar boa parte das opiniões expressas nas entrevistas, talvez muito mais do que qualquer característica inerente à tarefa em si.

0 perfil de aprendiz dos participantes manifesta-se sobretudo sob a forma dos estilos de aprendizagem evidenciados nos seus depoimentos. ${ }^{2}$ Os próprios entrevistados dão esteio a essa alegação, quando se referem às suas preferências pessoais sobre o processo de aprendizagem. Andréa e Helen, por exemplo, relacionam suas percepções da tarefa, o material e o meio utilizados aos seus estilos sensoriais de aprendizagem. Andréa diz: "Uma das características do tipo de aprendiz que eu sou... sou muito visual." Esta autoconsciência está claramente ligada a um comentário anterior de Andréa sobre sua percepção sensorial do material, na forma como ele se encontra exposto na tela do computador e sobre como isso interfere em sua disposição para lê-lo: Diz ela: "Sou muito visual, então se [a página] usasse diferentes formas de formatar os exemplos corretos e os de erros, aí talvez fosse mais fácil ler." Helen, por outro lado, depois de declarar que consegue "visualizar melhor na tela do que num livro", comenta que para os textos mais volumosos a estratégia muda, "porque texto [de literatura] eu geralmente começo marcando; eu vou sublinhando as partes que eu acho mais importantes". Notemos que esses dois exemplos revelam como as relações entre estilos, estratégias de aprendizagem e percepções sobre a tarefa são complexas e não unívocas; ambas as informantes são visuais, mas não o são da mesma maneira. É essa diferença que, acreditamos, pode estar na base de suas impressões a respeito da tarefa e do meio eletrônico em geral. Outra declaração dada por Andréa sustenta ainda mais nossa alegação no que

\footnotetext{
2 Para uma visão mais completa do conceito e das tipologias de estilos de aprendizagem ver Cyr (1998) ou a dissertação de mestrado do autor do presente texto, Oliveira (2002), capítulo 2.
} 
elas revelam sua consciência de suas próprias preferências. Ao comentar o conteúdo do material da internet ela diz: “[...] esses comentários que eu fiz são baseados no meu conhecimento de mundo, certo? Minha visão de mundo, então, pra mim, não fez sentido essas listas, todas de uma vez...". Se considerarmos que, nessa declaração, a informante está avaliando o valor da tarefa para a sua própria aprendizagem, então se torna claro o quanto a aluna é consciente das motivações de seu comportamento e percepção.

Andréa, Helen e Rita também aludem ao papel dos estilos de aprendizagem na sua execução e/ ou percepções da tarefa quando se referem a uma suposta superioridade da aprendizagem intuitiva, baseada na exposição das formas da língua, sobre a aprendizagem explícita e sistematizada de regras. É interessante observar que todas as três informantes, além de falantes fluentes da LE, declararam estar ensinando inglês havia pelo menos dois anos. Parece razoável sugerir que sua visão pode ser tanto um produto de suas histórias de aprendizes como de suas experiências como professoras e que essa é uma hipótese que merece ser investigada mais a fundo. Evidência adicional é dada por Craig, quando ele relata sua considerável experiência com cursos on-line na universidade, e uma vivência em uma universidade estrangeira que parece poder explicar em parte a sua resistência a certos usos da internet, assim como suas percepções da tarefa sobre o uso de artigos:

Uma das duas aulas que eu te falei sobre produção de texto era exatamente na Internet também. É... Eu não sei o quê que eu diria. Eu não sou uma pessoa... Eu gosto muito de usar a Internet, me ajuda muito na aprendizagem da língua, mas ainda tem alguma coisa no... não sei.. ainda tem alguma coisa que eu particularmente não me dou bem com a Internet e a aula. Não sei, fica muito vago, deveria ser mais específico, mas eu acho que eu to mais acostumado com o livro, com o professor conversando, a discussão mesmo. Por exemplo, uma dessas aulas que a gente fazia por computador, a sala, cada aluno tinha seu computador, todo mundo sentava de costas um pro outro no computador em vez de discutir o tema da aula a gente discutia por chat. Eu acho assim uma idiotice completa...

Outro fator que parece estar associado à disposição dos alunos para participar em atividades baseadas na internet é o seu contato prévio com o computador. Entretanto, isso não é suficiente para explicar muitas das reações dos informantes. Faz-se necessário 
considerar a natureza da experiência anterior com a CMC. Tanto Craig quanto Margarida declararam não ter computador em casa, mas enquanto ele declara ter contato freqüente com o meio eletrônico na universidade, ela diz que sua vivência resume-se apenas a um conhecimento "razoável" de software. Ao contrário do que esse contato com o meio eletrônico poderia sugerir, Margarida demonstra um entusiasmo muito maior em sua aprovação da tarefa on-line e da internet como recurso de aprendizagem do que Craig em sua reprovação desses meios. Todavia, o contato desse aluno com o meio eletrônico é bastante específico - incluindo uma experiência frustrante com outro curso via meio eletrônico - e, juntamente com suas preferências interacionais, parece muito mais influente do que a instrução de Margarida em software. Perguntamo-nos se a falta de veemência na desaprovação de Craig não seria um sinal de intimidação causado pelas diferenças de poder na relação entrevistado/ entrevistador; ou se haveria aí algum vínculo com sua personalidade aparentemente tímida. Por outro lado, a formação de Margarida em informática pode ser um índice do seu interesse especial por computadores, talvez explicando a sua aprovação entusiasta da tarefa e do uso da internet para o ensino/aprendizagem de LE. Essas evidências to rnam nossa suposição sobre o papel da experiência prévia mais provável do que considerar apenas o letramento eletrônico como um determinante.

Em suma, pudemos perceber que o perfil de aprendizagem do aluno, seu background educacional em geral e sua experiência profissional podem ter uma considerável influência sobre as percepções dos informantes de nossa pesquisa, assim como o contato já experienciado com o computador. A combinação desses três fatores talvez possa explicar por que uma mesma tarefa gerou opiniões tão diversas, por vezes expressando visões inteiramente opostas. Acreditamos que é a qualidade desses três fatores, associados no bojo da experiência de cada aprendiz que pode explicar as preferências e, conseqüentemente, suas percepções da tarefa on-line, muito mais do que a quantidade de experiência em cada fator específico. 


\section{Considerações finais}

A contribuição da Comunicação Mediada por Computador (CMC) para o ensino/aprendizagem de línguas, assim como para a pedagogia de uma forma geral, tem sido aclamada como geradora de mudanças significativas na sala de aula de LE, tanto no nível estritamente didáticocognitivo como no âmbito interacional. No primeiro caso, atribui-se à A prendizagem de Línguas Assistida por Computador (ALAC) o mérito de promover mais e melhores possibilidades de se atender às necessidades individuais de cada aprendiz, tais como adequação ao seu ritmo de aprendizagem, satisfação de suas curiosidades específicas, acessibilização de um número infindo de fontes de informação e dinamização das variáveis tempo e espaço no processo de aprendizagem. No âmbito interacional, apregoa-se o caráter democrático da ALAC, alegando-se que ela permite uma participação mais assídua e igualitária de todos os aprendizes, já que ela possibilitaria que o aluno tímido ou receoso de se expor superasse essas barreiras por estar em uma interação não presencial, ou, ao menos, não face a face.

0 nosso estudo confirma parte dessas alegações, mas também demonstra que nem todos os aprendizes consultados percebem como vantagens certos méritos atribuídos ao uso do meio eletrônico na sala de aula. Nosso estudo evidencia, também, que as diferenças entre como um e outro aprendiz percebe o meio eletrônico podem ter sua origem na experiência pessoal de cada aluno, seja ela educacional, seja profissional, em suas peculiaridades de aprendiz de línguas e em seu contato prévio com o computador. Desse modo, o chamado letramento eletrônico (computer literacy) seria apenas um dentre diversos fatores que podem explicar a variedade dessas percepções.

Acreditamos haver pelo menos uma razão mais abrangente para que se busque maior conhecimento desses tipos de fator da ALAC (como os alunos percebem e reagem às tarefas baseadas no uso do computador, o que eles percebem da complexidade das interações que se dão num ambiente eletrônico e quão clara é a sua consciência da importância dessas percepções), a saber: o computador e os recursos tecnológicos a ele associados ainda são uma novidade em nossas aulas de língua e, para muitos alunos, são uma concretitude restrita ao ambiente escolar que ainda não alcançou seus lares ou sua vida em geral. 0 quanto de letramento eletrônico adquirido fora da escola 0 
aluno traz para a sala de aula e quão influente na sua performance esse tipo de competência pode ser são questões de inegáveis implicações pedagógicas e, conseqüentemente, de grande interesse investigativo.

Com base em nosso estudo, tomamos as experiências prévias do aluno como aprendiz e mesmo como profissional da língua, experiências internas e externas à escola, como formadoras das percepções e disposição do aprendiz em relação à instrução assistida por computador. Consideramos, também, que o conjunto de tais percepções, associado a outros fatores, determina o desempenho do aluno no processo de aprendizagem, e, por isso mesmo, demanda maior atenção e investigação. Este texto é uma tentativa inicial de responder a questões relacionadas ao tema.

\section{Referências}

BARCELOS, Ana Maria Ferreira. A cultura de aprender línguas estrangeiras (inglês) de alunos forman dos de Letras. 1995. Dissertação (Mestrado em Lingüística Aplicada) - Universidade Estadual de Campinas, Campinas.

BELISLE, Ron. E-mail activities in the ESL Writing Class. Available from: http://www .aithech.ac.jp/ -iteslj/Articles/Belisle-Email.html. Cited: Jan. 2000.

CARVALHO, Valquíria C. P. S. de. A aprendizagem de língua estrangeira sob a ótica de alunos de Letras: crenças e mitos. 2000. Dissertação (Mestrado em Lingüística Aplicada ao Ensino de Línguas Estrangeiras) Faculdade de Letras da UFMG, Belo Horizonte.

CORBETT, A. (1998). Internet at braken hale school. Available from http:/ /wfs.eun.org/about/context/gp/brakeframe.html.

CYR, Paul. Lês stratégi es d'aprentissage. Anjou/Paris: Les Éditions CEC/Clé International, 1998.

GALIZZI, Letícia. Crenças de professores e escolas públicas de Belo Horizontes sobre a pren dizagem de línguas. 2000. Dissertação (Mestrado em Lingüística Aplicada ao Ensino de Línguas Estrangeiras) - Faculdade de Letras da UFMG, Belo Horizonte.

GRAUS, Johan. An evaluation of the usefulness of internet in the EFL classroom. 1999. Dissertação (Mestrado) - Department of English of the University of Nijmegen, Holanda. Available from http://home.plex.nl/ jgraus/ 
HO, Caroline Mei Lin. Developing intercultural awareness and writing skills through email exchange. The Internet TESL Journal, v. VI, n. 12, dez. 2000. Available from: http://www.aitech.ac.jp/ iteslj/Articles/HoEmail.html. Cited: 29 Jan. 2001.

HORWITZ, E. Surveying students beliefs about language learning. In: WENDEN, A.; RUBIN, J. Learner strategies in language learning. Englewood Cliffs: Prentice Hall, 1987.

ISBELL, Katharine; REINHARDT, Jon. A web-integrated course: a shared perception? Miyazaki International College, Japan, 10/11/1999. Available from: http://langue.hyper.chubu.ac.jp/jalt/pub/tlt/99/dec/isbell.html Cited: 30 Jan. 2001.

KOHL, John R. Article usage (2000). The Writing Center at Rensselaer Polytechnic Institute. Available from: http://rpi.edu/web/writingcenter/ esl.html Cited: 2 Sept. 2000.

LeLOUP, J.W. \& R. Ponterio. Basic Internet tools for foreign language educators. In: WARSCHAUER, M. (Ed.). Virtual connections: O nline activities $\&$ projects for networking language learners. Honolulu, HI: University of Hawaii Press, 1995.

LIAO, Chao-chih. E-mailing to improve EFL learners' reading and writing abilities: Taiwan experience. The Internet TESL Journal, v. V, n. 3, mar. 1999. Available from: http://www.aitech.ac.jp/ iteslj/Articles/LiaoEamiling.html Cited: 13 Dec. 1999.

OLIVEIRA, Roberval Araujo de. Percepções deapren dizes de inglês língua estrangeira sobretarefas de enfoque gramatical realizadas on-line. 2003. Dissertação (Mestrado em Lingüística Aplicada ao Ensino de Línguas Estrangeiras) - Faculdade de Letras da UFMG, Belo Horizonte.

PAIVA, Vera M. O. CALL and online journals. In: DEBSKY, R.; LEVY, M. (Org.). World CALL: Global perspectives on computer-assisted language learning. Lisse: Swets \& Zeitlinger B. V., p. 249-65, 1999.

PARREIRAS, Vicente Aguimar. Percepções de alunos da primeira série do ensino médio sobrea integração da In ternet à sala deaula de inglês. 2000. Dissertação (Mestrado em Lingüística Aplicada ao Ensino de Línguas Estrangeiras) - Faculdade de Letras da UFMG, Belo Horizonte.

PENNINGTON, Martha. The power of the computer in language education. In: PENNINGTON, Martha (Ed.). The Power of CALL. Hong Kong: Athelstan, 1996. 
PICA, Teresa. The article in American English: What the textbooks don't tell us. In: Wolfson, N.; Judd, E. (Ed.). Sociolinguistics and language acquisition. Rowley, MA: Newbury House, 1983. p. 222-233.

PUTNAM, Dawn. Student perception of computers as a writing tool. Available from: http://scnc.chelsea.k12.mi.us/ dputnam/Perception.html Cited: 11 Nov. 2000.

ROGER, C. Comenius likes the Web. Available from: http://wfs.eun.org/ about/context/wfs/comeniusframe.html, 1998.

VAN ASSCHE, F. The Web for schools project. Available from: http:// wfs.eun.org./about/context/wfs/projectframe.html, 1998.

WARSCHAUER, Mark. Interaction, negotiation and computer-mediated learning. University of Hawaii. Available from: http://www.insa-lyon.fr/ Departements/CDRL/interaction.html, 1998. Cited: 30 Sept. 1999.

WARSCHAUER, Mark; LEPEINTRE, Suzanne. Freire's dream or Foucault's nightmare?: Teacher-Student Relations on an International Computer Network. University of Hawaii, 1997. Available from: http://www.Ill. haw aii.edu/web/faculty/markw/freire.html. Cited: 30 Sept. 1999. 